\title{
Cardiovascular autonomic dysfunction in diabetes mellitus
}

\author{
L Barkai, L Madácsy
}

\begin{abstract}
The aim was to assess cardiovascular autonomic dysfunction in children and adolescents with diabetes mellitus. A total of 110 children and adolescents with type 1 (insulin dependent) diabetes (aged 6 to 18 years) and 130 non-diabetic controls were studied. Resting heart rate, heart rate variation to deep breathing, heart rate response to standing from a lying position, fall in systolic blood pressure on standing, and rise in diastolic blood pressure during sustained handgrip were measured. A reference range of results was obtained in the controls. Diabetic children had signifcantly increased resting heart rate [92.4 (SEM 2.5) v $84.2 \quad(2 \cdot 2)$ beats $/ \mathrm{min}$ ], decreased deep breathing heart rate variation $[25.3(0.9) v 32.8(0.6)$ beats $/ \mathrm{min}]$, and lower standing/lying heart rate ratio $[1.23(0.04) v 1.31(0.03)]$ compared with controls. 46 diabetic children $(42 \%)$ had at least one abnormal autonomic test result. Of these, $20(15 \%)$ had only one abnormal test and $26(24 \%)$ had two or more abnormal tests. Using multiple logistic regression analysis, longer diabetes duration and worse long term metabolic control were independently predictive of cardiovascular autonomic dysfunction as the dependent variable [adjusted OR (95\% CI): $2 \cdot 9(1 \cdot 1-5 \cdot 9)$ and $3 \cdot 3(1 \cdot 2-6 \cdot 4)$, respectively]. Cardiovascular autonomic dysfunction is not rare in children with diabetes. Efforts should be made to maintain the best metabolic control to prevent or delay these complications.

(Arch Dis Child 1995; 73: 515-518)
\end{abstract}

Keywords: autonomic dysfunction, diabetes mellitus, children.

II Department of

Paediatrics,

Postgraduate Medical

Faculty, Imre Haynal

University of Health

Sciences, Miskolc,

Hungary

L Barkai

I Department of

Paediatrics,

Semmelweis Medical

University, Budapest,

Hungary

L Madácsy

Correspondence to:

Dr L Barkai, II Departmen

of Paediatrics, Postgraduate

Medical Faculty, Imre

Medical Faculty, Imre

Haynal University of Health
Sciences, H-3501 Miskolc,

Sziences, H-3501 M,

Hungary.

Accepted 9 August 1995 possibly because the early signs of this diabetes in paediatric patients. ${ }^{7-10}$ The aim of this related complication are not often looked for study was to investigate the function of the autonomic nervous system in children and adolescents with type 1 (insulin dependent) diabetes to assess the prevalence of subclinical autonomic neuropathy in a paediatric diabetic population.

\section{Methods}

One hundred and ten children and adolescents with type 1 diabetes (aged 6 to 18 years; duration of diabetes ranging from one month to 16 years) and 130 healthy subjects were studied. The patients were recruited from the diabetes population regularly attending the diabetes outpatient clinic at our hospital. Since in Hungary all children and adolescents with diabetes within a geographic region attend the same hospital clinic, this material is unselected. The diabetic and healthy groups were matched for age, sex, body mass index (BMI), and height (table 1). All patients were being treated with combinations of short and intermediate acting human insulin injected two or four times daily. None of the subjects had any disorder apart from diabetes, and none had clinical symptoms of neuropathy or angiopathy. Neither the healthy nor the diabetic subjects had been treated with any drugs (except for insulin) during the study or during the preceding two weeks. A normal resting electrocardiogram was a condition for inclusion in the study groups. All subjects and their parents gave their informed consent, and the study was approved by the regional ethics committee.

Autonomic function was investigated by bedside cardiovascular tests. The cardiovascular tests employed included (1) mean resting heart rate (RHR) for a period of $1 \mathrm{~min}$; (2) heart rate variation to deep breathing (DBHR); (3) heart rate response to standing from a lying position (ratio of heart rate standing over heart rate lying, standing/lying ratio); (3) fall in systolic blood pressure on standing; and (5) rise in diastolic blood pressure during sustained handgrip. ${ }^{11}$ Heart rates were determined with a routine electrocardiographic device (Medicor ER 31-A, Budapest) by R-R intervals; for blood pressure measurements a

Table 1 Characteristics of the populations studied. Values are means (SD)

\begin{tabular}{lcc}
\hline & $\begin{array}{l}\text { Diabetes } \\
(n=110)\end{array}$ & $\begin{array}{l}\text { Control } \\
(n=130)\end{array}$ \\
\hline Gender (M/F) & $60 / 50$ & $65 / 65$ \\
Age (years) & $13 \cdot 0(2 \cdot 4)$ & $12 \cdot 5(2 \cdot 6)$ \\
BMI (kg/m $\left.{ }^{2}\right)$ & $18.9(0.8)$ & $19 \cdot 4(0 \cdot 9)$ \\
Height (cm) & $151 \cdot 3(4 \cdot 4)$ & $150 \cdot 8(5 \cdot 0)$ \\
Diabetes duration (years) & $6.0(3 \cdot 8)$ & - \\
\hline
\end{tabular}

$\mathrm{BMI}=$ body mass index. 
digital blood pressure device (Omron HEM$400 \mathrm{C}$, Tokyo) was used. Tests for autonomic function were performed by the same person (LB) at least two hours after blood glucose measurement and insulin injection. Patients had formal physical examination and pubertal assessment using Tanner criteria before autonomic function tests. ${ }^{12}$ Long term metabolic control was estimated by mean glycated haemoglobin level over one year measured three monthly.

Reference ranges for each cardiovascular test and cut off points for normal ranges were generated from data obtained in the healthy control group aged 6 to 18 years. After log transformation, sex, BMI, and height had no effect on cardiovascular tests. Age affected resting heart rate $(\log y=2.068-0.012 x$, $r=-0.892, \mathrm{p}<0.00001)$, standing/lying heart rate ratio $(\log \mathrm{y}=0.136-0.002 \mathrm{x}, r=-0.298$, $\mathrm{p}<0.01$ ), and sustained handgrip (log $\mathrm{y}=0.465+0.044 \mathrm{x}, \quad r=0.755, \mathrm{p}<0.001)$, but not DBHR $(\log \mathrm{y}=1.469+0.001 \mathrm{x}, r=0.016$, NS) or blood pressure fall on standing (log $\mathrm{y}=-0.509-0.005 \mathrm{x}, r=-0.012$, NS). The $95 \%$ confidence limits were considered as the limits of normality, and the following equations were used to define abnormal results for age dependent autonomic variables: resting heart rate $\left(P_{0.95}\right.$, beats $\left./ \mathrm{min}\right)=-2.499$ age $\quad$ (years $)+$ 131.769; standing/lying heart rate ratio $\left(P_{0.05}\right)=-0.007$ age (years) +1.198 ; handgrip $\left(P_{0.05}, \mathrm{~mm} \mathrm{Hg}\right)=0.857$ age (years) -9.363 . Reference limits are given in table 2 . Reproducibility of the autonomic tests was examined by reassessing five healthy subjects. Each subject was reassessed twice after the initial examination at two-week intervals. The mean and standard deviation of the three measurements for each person was calculated and the coefficient of variation expressed as a percent $(\mathrm{SD} / \mathrm{mean} \times 100)$. The coefficients of variation for the autonomic tests were as follows: resting heart rate $=8.8 \%$; DBHR $=6 \cdot 7 \%$; standing/lying heart rate ratio $=6.9 \%$; blood pressure fall on standing $=8.7 \%$; handgrip $=7 \cdot 2 \%$.

Capillary blood glucose concentrations were determined by means of a glucose reflectance meter (One Touch, Lifescan, Johnson and Johnson). Glycated haemoglobin was measured

Table 2 Reference limits for cardiovascular autonomic tests. Resting heart rate (RHR) higher than $P_{0.95}$ and heart rate response to standing $(S / L)$, blood pressure response to sustained handgrip (SH), heart rate variation to deep breathing (DBHR), and blood pressure response to standing (OT) lower than $P_{0.05}$ were considered as abnormal

\begin{tabular}{llllll}
\hline $\begin{array}{l}\text { Age } \\
\text { (years) }\end{array}$ & $\begin{array}{l}R H R \\
P_{0.95} \\
\text { (beats/min) }\end{array}$ & $\begin{array}{l}S / L \\
P_{0.05}\end{array}$ & $\begin{array}{l}S H \\
P_{0.05} \\
(\mathrm{~mm} H g)\end{array}$ & $\begin{array}{l}\text { DBHR } \\
P_{0.05} \\
\text { (beats/min) }\end{array}$ & $\begin{array}{l}\text { OT } \\
P_{0.05} \\
(\mathrm{~mm} \mathrm{Hg})\end{array}$ \\
\hline 6 & 117 & $1 \cdot 16$ & -4 & & \\
7 & 114 & $1 \cdot 15$ & -3 & & \\
8 & 112 & $1 \cdot 14$ & -3 & & \\
9 & 109 & $1 \cdot 14$ & -2 & & \\
10 & 107 & $1 \cdot 13$ & -1 & All & All \\
11 & 104 & $1 \cdot 12$ & 0 & 20 & -15 \\
12 & 102 & $1 \cdot 12$ & 1 & 20 & \\
13 & 99 & $1 \cdot 11$ & 2 & & \\
14 & 97 & $1 \cdot 10$ & 3 & & \\
15 & 94 & $1 \cdot 10$ & 4 & & \\
16 & 92 & 1.09 & 4 & & \\
17 & 89 & 1.09 & 5 & & \\
18 & 87 & 1.07 & 6 & & \\
\hline
\end{tabular}

Table 3 Cardiovascular autonomic test results in cohorts studied. Values are means (SEM)

\begin{tabular}{lll}
\hline & $\begin{array}{l}\text { Diabetes } \\
(n=110)\end{array}$ & $\begin{array}{l}\text { Control } \\
(n=130)\end{array}$ \\
\hline RHR (beats/min) & $92 \cdot 4(2 \cdot 5)^{\star}$ & $84 \cdot 2(2 \cdot 2)$ \\
DBHR (beats/min) & $25 \cdot 3(0 \cdot 9)^{\star \star}$ & $32 \cdot 8(0 \cdot 6)$ \\
S/L (mm Hg) & $1 \cdot 23(0 \cdot 04)^{\star}$ & $1 \cdot 31(0 \cdot 03)$ \\
OT (mm Hg) & $-5 \cdot 3(1 \cdot 8)$ & $-2 \cdot 5(1 \cdot 5)$ \\
SH (mm Hg) & $10 \cdot 9(1 \cdot 3)$ & $12 \cdot 8(1 \cdot 3)$ \\
\hline
\end{tabular}

$\mathrm{RHR}=$ resting heart rate; $\mathrm{DBHR}=$ heart rate variation to deep breathing; $\mathrm{S} / \mathrm{L}=$ heart rate response to standing; $\mathrm{SH}=$ blood pressure response to sustained handgrip; $\mathrm{OT}=$ blood pressure response to standing.
${ }^{\star} \mathrm{p}=0.05 ;{ }^{\star \star} \mathrm{p}=0.01$.

by an ion capture assay (IMx glycated haemoglobin assay, Abbot Laboratories). Normal range is between 4.8 and $7.8 \%$ glycated haemoglobin.

\section{STATISTICS}

Clinical characteristics of study groups are given as mean (SD) and results are expressed as mean (SEM). Distribution was tested for each variable by Kolmogorov-Smirnov test. Differences between the non-diabetic and diabetic groups were tested by $\chi^{2}$ test and the Student's $t$ test or Mann-Whitney rank sum test for normal or non-normal data, respectively. Statistical associations were established by linear regression analysis for continuous data. Multiple logistic regression analysis was applied for discrete binary variables and odds ratios with $95 \%$ confidence intervals were calculated. Differences at the $5 \%$ level were considered significant.

\section{Results}

Diabetic children had a significantly higher resting heart rate, decreased deep breathing heart rate variation, and lower standing/lying heart rate ratio compared with healthy control children. Orthostatic and sustained handgrip tests did not differ between the two groups (table 3).

Using reference ranges obtained in the healthy subjects, 46 diabetic children (42\%) had at least one abnormal autonomic test result. Of these, $20(15 \%)$ had only one abnormal test and $26(24 \%)$ had two or more abnormal tests. The frequency of abnormal results of the different tests were as follows: DBHR, $\mathrm{n}=23$ cases $(21 \%)$; resting heart, $\mathrm{n}=18$ cases $(16 \%)$; standing/lying heart rate ratio, $n=17$ cases $(16 \%)$; blood pressure fall on standing, $n=15$ cases ( $14 \%$ ); and blood pressure rise on sustained handgrip, $n=6$ cases $(6 \%)$. In the healthy group, seven cases $(5 \%)$ showed an abnormal test result, but none of them had two or more abnormal tests.

Characteristics of patients assigned into two groups according to the presence or absence of abnormal autonomic test results can be seen in table 4. Patients with abnormal autonomic test results were older, had a longer duration of diabetes, and had higher glycated haemoglobin than those with normal autonomic function. Using multiple logistic regression analysis, diabetes duration ( $>8 v<4$ years) and mean 
Table 4 Differences between diabetic patients with and without abnormal cardiovascular autonomic test result. Values are means (SEM)

\begin{tabular}{lcc}
\hline & $\begin{array}{l}\text { With } \\
\text { abnormal } \\
\text { autonomic test } \\
(n=46)\end{array}$ & $\begin{array}{l}\text { Without } \\
\text { abnormal } \\
\text { autonomic test } \\
(n=64)\end{array}$ \\
\hline Age (years) & $14 \cdot 2(0 \cdot 9)^{\star}$ & $12 \cdot 0(1 \cdot 0)$ \\
Gender (M/F) & $24 / 22$ & $36 / 30$ \\
Pubertal stage $\left.\left(\mathrm{T}_{1-3}\right) / \mathrm{T}_{4-5}\right)$ & $12 / 34$ & $22 / 42$ \\
Height $(\mathrm{cm})$ & $152 \cdot 4(1 \cdot 6)$ & $149 \cdot 9(1 \cdot 4)$ \\
Diabetes duration (years) & $7 \cdot 6(1 \cdot 2)^{\star \star}$ & $4 \cdot 1(1 \cdot 3)$ \\
Closest GHb (\%) & $11 \cdot 6(1 \cdot 2)^{\star}$ & $8 \cdot 7(1 \cdot 1)$ \\
Mean GHb over 1 year (\%) & $12 \cdot 0(1 \cdot 3)^{\star}$ & $8 \cdot 5(1 \cdot 5)$ \\
Daily dose of insulin (U/kg) & $0 \cdot 93(0 \cdot 1)$ & $0 \cdot 87(0 \cdot 1)$ \\
Blood glucose (mmol/litre) & $10 \cdot 2(1 \cdot 1)$ & $9 \cdot 7(1 \cdot 0)$ \\
\hline GHb=glycated haemoglobin. & & \\
${ }^{\star} \mathrm{p}=0 \cdot 05 ; \star{ }^{\star} \mathrm{p}=0.01$. & &
\end{tabular}

glycated haemoglobin measured over 1 year $(>12 v<8 \%$ ) proved to be independently predictive of the presence of at least one abnormal autonomic test result when the latter was entered as the dependent variable [adjusted OR (95\% CI): 2.9 (1.1-5.9), $p=0.02$, and $3.3(1.2-6.4), p=0.01$, respectively]. Age, gender, pubertal stage, height, insulin dosage, and actual blood glucose level were not associated with autonomic dysfunction in this multivariate analysis.

\section{Discussion}

In this study we found increased resting heart rate, decreased heart rate variation to deep breathing, and diminished heart rate response to standing in diabetic children and adolescents as early signs of autonomic dysfunction. Moreover, an abnormal cardiovascular autonomic test result was found in $42 \%$ and $5 \%$ in the diabetic and healthy populations, respectively. Two or more abnormal test results were observed in $24 \%$ of the diabetic group and none of the healthy control group. Cardiovascular autonomic abnormality was associated with longer duration of diabetes and worse long term metabolic control.

Previous studies have suggested that many children with diabetes have autonomic dysfunction, even after a short duration of disease. ${ }^{5710}$ However, data on the influence of diabetes duration and metabolic control on autonomic abnormalities in children are conflicting. Young et al found that diabetic teenagers with abnormal autonomic tests had a longer mean duration of diabetes and a higher HbAl concentration than those with normal tests, though neither of these differences was statistically significant. ${ }^{5}$ On the other hand, progression was observed in those who had poor glycaemic control. ${ }^{13}$ In studies by Mitchell et al and by Aman et al, tests for cardiovascular autonomic function did not correlate with the duration of diabetes or metabolic control. ${ }^{414}$ In another study by Jenkins $e t$ $a l$, heart rate variability correlated well with the duration of diabetes and with metabolic control. ${ }^{9}$ Aagenaes et al found that heart rate response to standing was related to the duration of diabetes, ${ }^{8}$ and a very recent study by Akinci et al found an association between low heart rate variability and poor metabolic control. ${ }^{15}$ Our present findings support the view that the development of neurological complications depends on the duration and long term metabolic control of diabetes. ${ }^{16}$ It has been suggested that sex differences and pubertal changes are important factors related to the pathogenesis of microvascular complications of diabetes. ${ }^{17} 18$ Male gender and advancement of pubertal stages have also been associated with peripheral neuropathy. ${ }^{19}$ In contrast to these data, autonomic neuropathy assessed by pupillometry did not seem to be related to puberty. ${ }^{20}$ Our present study shows that autonomic dysfunction was not affected by sex and pubertal stages.

In the present study the most common abnormal result was the deep breathing test (predominantly parasympathetic function), while the orthostatic and sustained handgrip tests (sympathetic function) were less frequently affected. This finding suggests that during the course of diabetes parasympathetic dysfunction may appear earlier than sympathetic damage, as has been suggested elsewhere. ${ }^{21}$ However, the deep breathing test proved to be most sensitive in detecting autonomic neuropathy, and this could be the explanation for the high prevalence of abnormal findings in this test observed in our study. 2223

It has been suggested that adult diabetic patients with impaired autonomic nervous system function have an increased mortality rate compared to the general diabetic population and they are at greater risk for sudden death and arrhythmias. ${ }^{32425}$ Recently, an association between abnormal cardiovascular autonomic test results and severe hypoglycaemia was observed in young diabetic patients, and it seems that disturbed autonomic function may contribute to blood pressure alterations in children and adolescents with diabetes. ${ }^{26} 27$ Nevertheless, whether early abnormalities in autonomic function will prove accurate predictors of later symptomatic autonomic neuropathy, with its poor prognosis, is unknown at present. Further prospective studies are necessary to answer this question.

In conclusion, cardiovascular autonomic dysfunction as a form of autonomic neuropathy is not rare in children and adolescents with diabetes. Longer duration of diabetes and worse long term metabolic control are risk factors for cardiovascular autonomic dysfunction. Assessment of autonomic nervous system function should be part of the screening programme for diabetic complications. Efforts should be made to maintain the best possible metabolic control in order to prevent or delay this diabetes related complication.

Presented in part at the First European Paediatric Congress, Paris/France, 9-11 March, 1994

1 Hilsted J, Jensen SB. A simple test for autonomic neuropathy in juvenile diabetics. Acta Med Scand 1979; 205: 385-7.

2 Clements RS, Bell DSH. Diagnostic, pathogenetic, and therapeutic aspects of diabetic neuropathy. Spec Top Endocrinol Metab 1982; 3: 1-43.

3 Ewing DJ, Campbell IW, Clarke BF. Assessment of cardiovascular effects in diabetic autonomic neuropathy and prognosis implications. Ann Intern Med 1980; 92: 308-11.

4 Mitchell EA, Wealthall SR, Elliott RB. Diabetic autonomic neuropathy in children: immediate heart rate response to standing. Aust Paediatr f 1983; 19: 175-7. 
5 Young RJ, Ewing DJ, Clarke BF. Nerve function and metabolic control in teenage diabetics. Diabetes 1983; 32 142-7.

6 Barkai L, Szabó L. Urinary bladder dysfunction in diabetic children and adolescents with and without subclinical cardiovascular autonomic neuropathy. Eur f Pediatr 1993; 152: 190-2.

7 Mitchell EA, Wealthall SR, Elliott RB. Tests for autonomic neuropathy in diabetic children. Aust Paediatr f 1985; 21: 105-9.

8 Aagenaes $\mathrm{O}$, Aabech $\mathrm{H}$, Lofthang IJ. Autonomic neuropathy in children and young adults. Pediatr Adolesc Endocrinol 1981; 9: 287-91.

9 Jenkins JG, Carson DJ, McClure BG, Sharif B, McCready $\mathrm{P}$, Mitchell RH. Heart rate variability in young diabetics. Pediatr Adolesc Endocrinol 1989; 18: 42-6.

10 Barkai L, Madácsy L, Kassay L. Investigation of subclinical signs of autonomic neuropathy in the early stage of childhood diabetes. Horm Res 1990; 34: 54-9.

11 Ewing DJ, Clarke BF. Diagnosis and management of diabetic autonomic neuropathy, $B M 7$ 1982; 285: 916-8.

12 Tanner JM. Growth at adolescence, 2nd Ed. Oxford: Blackwell, 1962.

13 Young RJ, Macintyre CCA, Martyn CN, et al. Progression of subclinical polyneuropathy in young patients with type 1 (insulin-dependent) diabetes: associations with type 1 (insulin-dependent) diabetes: associations with glycaemic control and microangiopathy (micto
complications). Diabetologia 1986; 29: 156-61.

14 Aman J, Eriksson E, Lideen J. Autonomic nerve function in children and adolescents. Clin Physiol 991; 11: 537-43.

15 Akinci A, Celiker A, Baykal E, Tezic T. Heart rate variability in diabetic children: sensitivity of the time- and frequency-domain methods. Pediatr Cardiol 1993; 14 140-6.

16 The Diabetes Control and Complications Trial Research Group. The effect of intensive treatment of diabetes on the development and progression of long-term complications in insulin-dependent diabetes mellitus. N Engl f Med 1993; 329: 977-86.

17 Ewald U, Tuvemo T. Reduced vascular reactivity in diabetic children and its relation to diabetic control. Acta Paediatr Scand 1985; 74: 77-84.

18 Rogers DG, White NH, Shalwitz RA, Palmberg P, Smith ME, Santiago JV. The effect of puberty on the development of early diabetic microvascular disease in insulinmependent diabetics. Diabetes Res Clin Pract 1987; 3: 39-44.

19 Sosenko JM, Boulton AJ, Kubrusly DB, Weintraub JK, Skyler JS. The vibratory perception threshold in young diabetic patients: associations with glycemia and puberty Diabetes Care 1985; 8: 605-7.

20 Clarke CF, Piesowicz AT, Spathis GS. Pupillary size in children and adolescents with type 1 diabetes. Diabetic Med 1989; 6: 781-3

21 Ewing DJ, Campbell IW, Clarke BF. Heart rate changes in diabetes mellitus. Lancet 1981; i: 183-5.

22 Pfeifer MA, Cook D, Brodsky J, et al. Quantitative evaluation of cardiac parasympathetic activity in normal and diabetic man. Diabetes 1982; 31: 339-45.

23 Fisher BM, Frier BM. Usefulness of cardiovascular tests of autonomic function in asymptomatic diabetic patients. Diabetes Res Clin Pract 1989; 6: 157-60.

$24 \mathrm{Kahn} \mathrm{JK}$, Sisson JC, Vinik AI. QT interval prolongation and sudden cardiac death in diabetic autonomic neuropathy. sudden cardiac death in diabetic autono
$\mp$ Clin Endocrinol Metab 1987; 64: 751-4.

25 Bellavare F, Ferri M, Guarini L, et al. Prolonged QT period in diabetic autonomic neuropathy: a possible role in in diabetic autonomic neuropathy: a possible rol

26 Barkai L, Madácsy L, Vámosi I. Autonomic dysfunction and severe hypoglycaemia in insulin dependent diabetes mellitus. Arch Dis Child 1991; 66: 1438-41.

27 Madácsy L, Yasar A, Tulassay T, et al. Relative nocturna hypertension in children with insulin-dependent diabetes mellitus. Acta Paediatr 1994; 83: 414-7. 